International Journal of Science, Engineering, and

Information Technology

Volume 05, Issue 02, December 2020

Journal homepage https://Journal.trunojoyo.ac.id/ijseit

\title{
Analysis Of Load Variations On ST 60 Steel Using Vickers Method
}

\author{
Hidayat $^{\mathrm{a}}$, Moh.Jufriyanto ${ }^{\mathrm{b}}$, Akhmad Wasiur Rizqi ${ }^{\mathrm{c}}$, Alviani Hesthi Permata Ningtyas ${ }^{\mathrm{d}}$, \\ Rifky Maulana Yusron ${ }^{\mathrm{e}}$ \\ ${ }^{a b c}$ Department of Industrial Engineering, University of Muhammadiyah Gresik, Gresik, Indonesia. \\ ${ }^{\mathrm{d}}$ Department of Mechanical Engineering, University of Muhammadiyah Gresik, Gresik, Indonesia \\ ${ }^{\mathrm{e}}$ Department of Mechanical Engineering, University of Trunojoyo Madura, Bangkalan, Indonesia.
}

\begin{abstract}
A B S T R A C T
The use of metal in the industrial world, especially ST60 Steel, is a very vital need, this can be seen from the increasing number of machine or equipment components or construction parts made of steel. Hardness is one of the mechanical properties that is often used as a guide in selecting materials for an equipment component. To find out the hardness price of a material, various testing methods can be used, including the Vickers method, which is tested by applying a force to the indented diamond pyramid against the material for which the hardness value is determined. The amount of hardness value is determined by the magnitude of the loading force divided by the area of indentation. In this study, what was investigated was the effect of force on the hardness of the Vickers method. The results showed that the load variation had little effect on the results of the Vickers hardness value, especially for high loads (100 Kgf). The average hardness value for the mild steel being tested is $163 \mathrm{HV}$ and $168 \mathrm{HV}$, the highest hardness value is $174 \mathrm{HV}$ and the lowest hardness value is $156 \mathrm{HV}$, so that a tolerance of $\pm 10 \mathrm{HV}$ commonly used in the Vickers test is sufficient.
\end{abstract}

Keywords: Hardness, ST 60 Steel, Loading Variations, Vickers Test

Article history

Received 01 November 2020

Received in revised form 12 November 2020

Accepted 28 November 2020

\section{Introduction}

The use of metal in the industrial world, especially ST60 Steel, is a very vital need, this can be seen from the increasing number of machine or equipment components or construction parts made of steel, so that the demand for steel is increasing [1]. In selecting materials or steel for the purpose of manufacturing components as mentioned above, technical requirements are required, including the mechanical properties of the material, namely: strength, ductility, hardness, etc. Hardness is one of the mechanical properties that is often used as a parameter in the selection of materials for component manufacturing machine [2]. To find out the hardness value of a material, a hardness test is carried out on the material using an appropriate method. In the Vickers method, the presentation is done by applying a force to the diamond pyramid with an angle of $136^{\circ}$ which is emphasized on the surface being tested, the value of hardness is determined by dividing the force exerted by the surface area of the former identification [6][7]. Based on the background of research, we try to examine the effect of load variations on the hardness of ST 60 steel using vickers method.

\section{Literature Review}

\subsection{Carbon Steel}

Carbon steel is a type of ferrous metal with limited amounts of carbon (C) sulfur (S), phosphorus (P), silicon $(\mathrm{Si})$, manganese $(\mathrm{Mn})$, etc. The properties of steel in general are strongly influenced by the percentage of carbon and microstructure. The microstructure of carbon steel is influenced by heat treatment and steel composition. Carbon with other alloys in steel forms

*Corresponding author

E-mail address : hidayat@umg.ac.id 
carbides which can increase the hardness, scratch resistance and temperature resistance of the steel. The difference in the percentage of carbon in a mixture of carbon steel is one way to describe the content of steel [3]. Based on the carbon content, steel is divided into three types, namely:

\subsubsection{Low Carbon Steel}

Low carbon steel (low carbon steel) contains less than $0.3 \%$ carbon in the alloy steel. This steel is not a hard steel because of its low carbon content of less than $0.3 \% \mathrm{C}$. Low carbon steel cannot be hardened because its carbon content is not sufficient to form a martensite structure.

\subsubsection{Medium Carbon Steel}

Medium carbon steel contains $0.3 \% \mathrm{C}-0.6 \% \mathrm{C}$ carbon with its carbon constituents allowing the steel to be partially hardened by suitable heat treatment. Medium carbon steel is harder and stronger than low carbon steel.

\subsubsection{High Carbon Steel}

High carbon steel contains $0.6 \%-1.5 \%$ carbon and has high hardness but lower ductility, it is almost impossible to know the distance between its melt stress and proportional stress on the stress-strain graph. In contrast to low carbon steels, heat-treated hardening of high carbon steels does not provide optimal results because there is too much martensite to make the steel brittle. The mechanical properties of steel are also influenced by the way in which carbon bonds with iron. According to Schonmetz. there are 3 main forms of crystals when carbon bonds with iron, namely:

1. Ferrite, namely pure iron (Fe), is located close to each other irregularly, both in shape and size. Ferrite is the softest part of steel, pure ferrite will not be suitable for use as a material for workpieces that bear loads because of its small strength.

2. Perlite, is a mixture of ferrite and cementite with a carbon content of $0.8 \%$. The perlitis structure has ferrite crystals itself from fine cementite flakes side by side in a thin layer.

3. Carbide iron (Fe3C), a chemical compound between iron and carbon as a separate structure called cementite. The increase in carbon content will increase the cementite levels. Cementite in steel is the hardest element.

\subsection{ST 60 steel}

ST 60 steel is a class of medium carbon steels that have a carbon content of $0.4644 \%$.

Table 1. Mechnical property for ST60-2 Low alloy steel:

\begin{tabular}{|c|c|c|c|c|c|}
\hline \multicolumn{6}{|c|}{ Thickness (mm) } \\
\hline St60-2 & $\leq 16$ & $\begin{array}{l}>16 \leq \\
40\end{array}$ & $\begin{array}{l}>40 \leq \\
63\end{array}$ & $\begin{array}{l}>63 \leq \\
80\end{array}$ & $>80$ \\
\hline \multirow[t]{2}{*}{$\begin{array}{l}\text { Yield } \\
\text { strength } \\
(\geq \mathrm{Mpa})\end{array}$} & 335 & 325 & 315 & 305 & 295 \\
\hline & $<3$ & \multicolumn{3}{|c|}{$\geq 3 \leq 100$} & $>100$ \\
\hline $\begin{array}{l}\text { Tensile } \\
\text { strength } \\
\text { (Mpa) }\end{array}$ & $\begin{array}{l}590- \\
770\end{array}$ & \multicolumn{3}{|c|}{$570-710$} & $\begin{array}{l}570- \\
710\end{array}$ \\
\hline \multicolumn{6}{|c|}{$\begin{array}{c}\text { Table 2. Chemical composition for St60-2 Low alloy } \\
\text { steel (Product Analysis Max\%) }\end{array}$} \\
\hline \multicolumn{6}{|c|}{ Main chemical elements composition of St60-2 } \\
\hline $\mathrm{C}$ & $\mathrm{Si}$ & $\mathrm{Mn}$ & $\mathrm{P}$ & $\mathrm{S}$ & $\mathrm{N}$ \\
\hline 0.40 & 0.60 & 1.70 & 0.060 & 0.060 & 0.010 \\
\hline
\end{tabular}

\subsection{Vickers Method}

The Vickers hardness test method is carried out by pressing the test object or specimen with a pyramidshaped diamond indenter with a square base and the angle of the faces facing $136^{\circ}$. Emphasis by the indenter will produce a trace or indentation on the surface of the specimen [4].

$$
\mathrm{BHN}=\frac{2 \mathrm{P}}{\pi \mathrm{D}\left[\left(\mathrm{D}-\sqrt{\left(\mathrm{D}^{2}-d^{2}\right)}\right]\right.}
$$

$\mathrm{P}=$ Load given (KP or $\mathrm{Kgf})$

$\mathrm{D}=$ Diameter of the indenter used

\subsection{Vickers Testing Standards}

The Vickers hardness testing standards are fully described in the following standards [8],

a) ASTM E92: Standard Vickers hardness testing method for materials metal.

b) ASTM E384: Standard micro-hardness testing method for materials

c) ISO 6507-1: Metallic materials - Vickers hardness testing - Part 1 - Test method.

d) ISO 6507-2: Metallic materials - Vickers hardness testing - Part 2 Verification and calibration of testing machines.

e) ISO 6507-3: Metallic materials - Vickers hardness testing - Part 3-Calibrate the reference beam. 
f) ISO 6507-4: Metallic materials - Vickers hardness testing - Part 4 - Hardness value table.

\subsection{Writing the Vickers hardness figures}

The method of writing Vickers hardness is usually written in the form of a number followed by the letters HV (Hardness Vickers) and the amount of the test load. For example: $186 \mathrm{HV} 30$, which means that the hardness number of the material being tested is 186 , the test load used is $30 \mathrm{kgf}$, and the dwell time is $10-15$ seconds. If the application time of the load is not between 10 and 15 seconds, the time to apply the test load must be stated. Example: 472 HV 50/20, meaning that the hardness number of the test object is 472 , the amount of test load applied is $50 \mathrm{kgf}$, and the length of time to apply the load is 20 seconds [5].

\subsection{Advantages and disadvantages of Vickers hardness} testing

Compared to other hardness tests, Vickers hardness testing has several advantages as well as disadvantages (disadvantages), as follows.

\section{Advantages:}

a) Using only one type of indenter for testing soft to hard materials

b) More accurate trace size readings can be made.

c) This type of test is relatively non-destructive.

d) The Vickers method can be used on almost any metal.

\section{Disadvantages:}

a) Overall, the test execution time is long.

b) Requires optical diagonal measurement of the trace.

c) The surface of the specimen must be well prepared

In addition to testing macro hardness, the Vickers method can also be used to carry out microhardness testing (Vickers microhardeness test). The test load ranges used in the Vickers microhardness test are small, ranging from $1 \mathrm{gf}$ to $1000 \mathrm{gf}$ (1 kgf). Vickers microhardness testing is particularly suitable for thin, surface-hardened layers of specimens, ceramics and composites [9].

\section{Research Method}

Research Variables The variables in this study are: - Independent variable: Force $(\mathrm{F})$ - Dependent variable: price of violence. Equipment Used ZME-2509B-The material used is ST 60 Steel.
Data collection techniques In this study, 3 experiments were carried out and each experiment was 3 specimens, the experimental steps were in the following order:

a) Install the base of the test object.

b) Set the handle or lever in position.

c) Install the indenter on the seat, and tighten the submerged nut using the key $\mathrm{L}$.

d) Select the load according to the specified variation

d. Install a suitable magnifying lens, opening the top cover first.

e. Place the test object on the base and tighten slightly by turning the Hand Whell.

f. Turn on the lamp.

g. Move the lever from position 1 to position 2 and check the accuracy of the penetrator, then to position 3 slowly (is the initial load)

h. Move the lever again to position 4, wait a few moments 2030 seconds until the hour hand is still

i. Move the lever back to position 1 .

j. Measure the indentation that is visible on the glass a loupe with a ruler whose magnification matches the lens

Data Analysis Techniques The techniques used for data processing are statistical analysis of variance and standard deviation with upper control limits and lower control limits.

\section{Result and Discussion}

Research Data Hardness data $\{\mathrm{HV}\}$ calculation results obtained from the calculation results obtained data on hardness $\{\mathrm{HV}\}$ as in the following table:

Table 4.Hardness Data

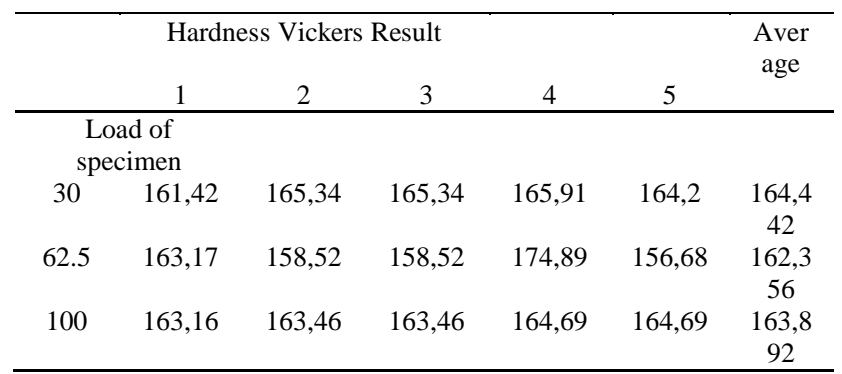

Data processing

Table 5. Testing at a load of $30 \mathrm{Kgf}$

\begin{tabular}{ccccc}
\hline Specimen & Measuremen & Deviation & $\begin{array}{c}\text { Squared } \\
\text { Deviation }\end{array}$ & $\begin{array}{c}\text { Squares } \\
\text { Measurem } \\
\text { ent }\end{array}$ \\
\hline 1 & 165,2 & $+0,76$ & 0,58 & $26.961,60$ \\
2 & 164,3 & $-3,12$ & 9,73 & $25.702,50$ \\
3 & 166,91 & $+2,47$ & 6,1 & $27.702,10$ \\
4 & 165,5 & $+1,9$ & 3,6 & $27.337,30$ \\
5 & 162,6 & $-2,02$ & 4,08 & $26.056,40$ \\
total & 817,19 & 0 & 24,1 & 133.584 \\
\hline
\end{tabular}

$\mathrm{UCL}=163,170+2(7,105)=177,38$

$\mathrm{LCL}=163,170-2(7,105)=148,96$ 


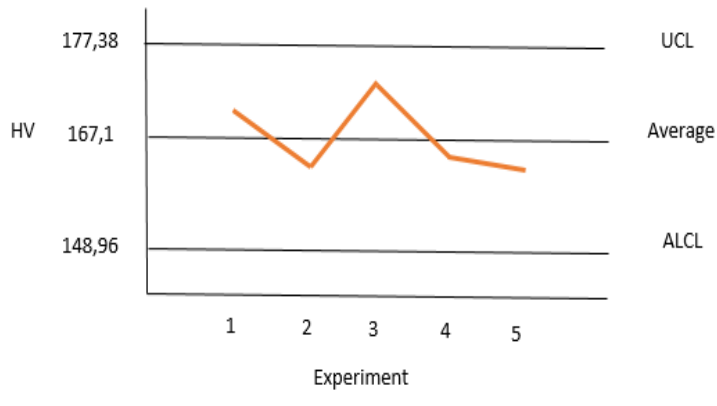

Table 6. Testing at $100 \mathrm{Kgf}$ load

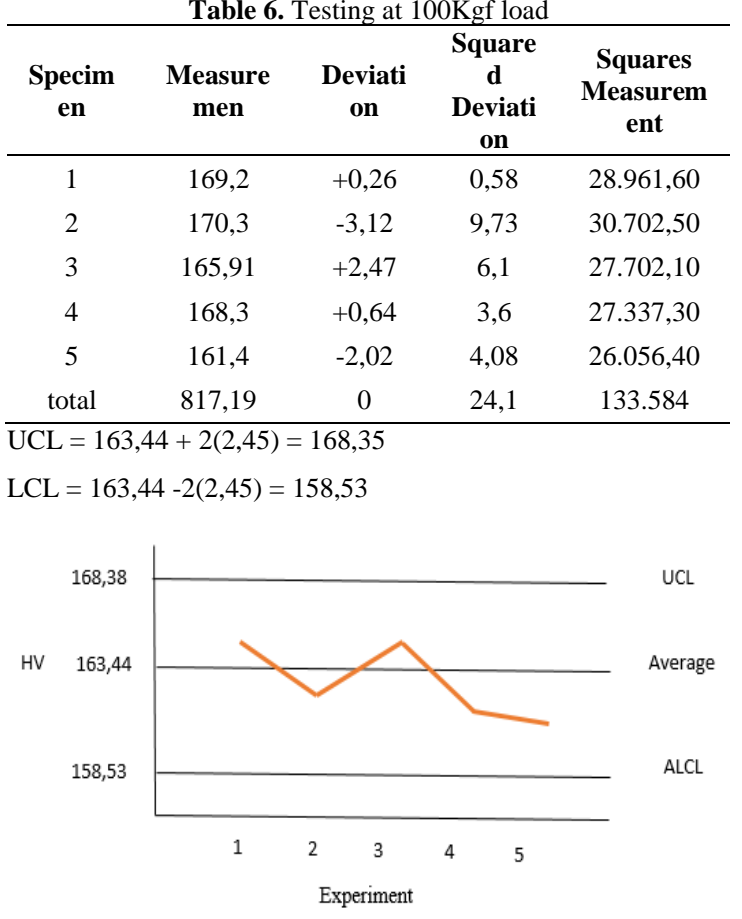

Table 6. Testing at 62,5 Kgf load

\begin{tabular}{ccccc}
\multicolumn{5}{c}{ Table 6. Testing at 62,5 Kgf load } \\
\hline $\begin{array}{c}\text { Specim } \\
\text { en }\end{array}$ & $\begin{array}{c}\text { Measure } \\
\text { men }\end{array}$ & $\begin{array}{c}\text { Deviati } \\
\text { on }\end{array}$ & $\begin{array}{c}\text { Square } \\
\text { d } \\
\text { Deviati } \\
\text { on }\end{array}$ & $\begin{array}{c}\text { Squares } \\
\text { Measurem } \\
\text { ent }\end{array}$ \\
\hline 1 & 164,4 & $+0,26$ & 0,58 & $26.761,60$ \\
2 & 165,3 & $-3,12$ & 9,73 & $27.702,50$ \\
3 & 162,91 & $+2,47$ & 6,1 & $28.702,10$ \\
4 & 163,3 & $+0,64$ & 3,6 & $29.337,30$ \\
5 & 166,4 & $-2,02$ & 4,08 & $22.056,40$ \\
total & 825,19 & 0 & 24,1 & 144.586 \\
\hline $\mathrm{UCL}=163,44+2(2,45)=204,268$ & &
\end{tabular}

$\mathrm{LCL}=163,44-2(2,45)=132,056$

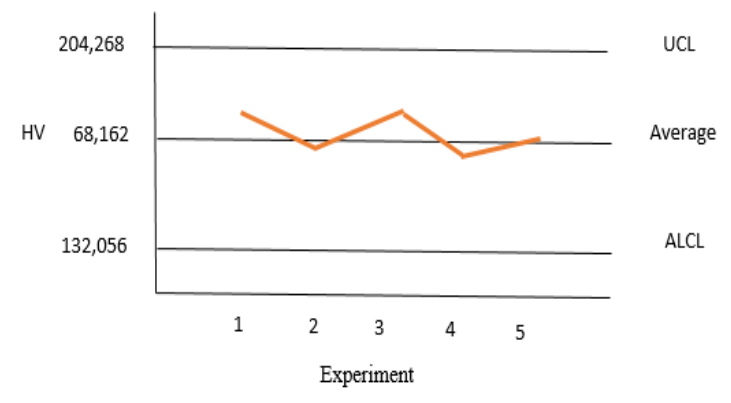

The three load variations used for the hardness test of the Vickers method, the average hardness value is very close to $163 \mathrm{HV}$ $168 \mathrm{HV}$. For tests with a load of $30 \mathrm{kgf}$ and $60 \mathrm{kgf}$ the results are very close to very close while the test with a load of $100 \mathrm{kgf}$ results slightly higher, It is possible that there is strain hardening on the indentation because with a heavy load it will result in a deep indentation (a greater degree of deformation). If you look at the deviation of the book, the heavier the load given the greater the price, this is also possible for the same effect. And the average hardness results are very close, and the tolerance that is usually given to the Vickers tester is approximately $10 \mathrm{HV}$, so even though the load is varied the results are relatively the same (enter tolerance). But if. If it is seen that there is the effect of strain hardding, it is advisable to use a low load test for weak materials and vice versa for hard materials to use a high load.

\section{Conclusion and Suggestion \\ 5.1 Conclusion}

Based on the research results it can be concluded that Variations in the load or force in the Vickers method test did not have much effect on the hardness (HV) test results. The hardness test results of the mild steel tested were an average of about $163 \mathrm{HV}$ and 168 $\mathrm{HV}$, with a tolerance of approximately $10 \mathrm{HV}$, all test results were satisfactory for mild steel. For mild steel, the greater the load used will produce a slightly higher hardness value. This result is possible due to strain hardening.

\subsection{Suggestion}

Based on the research results it can be suggested below:

1. In the Vickers method test, the load should be adjusted to the type of material being tested, if the load being tested is soft use a low load and if the material being tested is hard use a higher load.

2. This research needs to be followed up on other types of materials

\section{REFERENCES}

[1] Callister, W., "Materials Science and Engineering: An Introduction", USA: John Wiley and Sons, 2006.

[2] Liang, K. M., Orange, G. and Fantozzi, G., "Evaluation by Indentation of Fracture Toughness of Ceramic Materials", Journal of Materials Science, Vol. 25, 2004, pp. 207-214.

[3] ASTM E140-05e1, "Standard Hardness Conversion Tables for Metals Relationship Among Brinell Hardness, Vickers Hardness, Rockwell Hardness, Superficial Hardness, Knoop Hardness, and Scleroscope Hardness", ASTM International, 2005 .

[4] Solution for Automatic Microstructures Analysis from Images Based on a Backpropagation Artificial Neural Network", Nondestructive Testing and Evaluation, Vol. 23, 2008, pp. 273283. 
[5] Imasogie, B. I., Wendt, U., "Characterization of graphite particle shape in spheroidal graphite iron using a computer based image analyzer", Journal of Minerals \& Materials Characterization \& Engineering, Vol. 3, 2004, pp 1-12.

[6] Li, P. and Xiao, X., "An Unsupervised Marker Image Generation Method for Watershed Segmentation of Multispectral Imagery”, Geosciences Journal, Vol. 8, 2004, pp. 325-331. [14] Yao, L. and Fang, C. H., "An Automatic Hardness Measuring Method using Hough Transform and Fuzzy C-Means Algorithm”, IEEE Transactions on Industrial Electronics, Vol. 3, 2001, pp. 842-847.

[7] Aydemir B., Sertlik Olcum Yontemlerinin Bugunu ve Yarini, Metal Dunyasi, Sayi 189,Sayfa 84-87, 2009

[8] Bora M.O., Coban O., Sinmazcelik T., Gunay V., Zeren M., Materials and Design 312707-2715, 2010

[9] EN ISO 14577-1,2002, Metallic materials--Instrumented indentation test for hardnessand materials parameters--Part 1: Test method. 